\title{
MAKE IN INDIA AND DELHI-MUMBAI INDUSTRIAL CORRIDOR (DMIC)
}

\author{
Sharad Ranganath Darandale \\ Arts, Commerce \& Science College, Sonai.Tal. Newasa, Dist. Ahmednagar. \\ Corresponding Author: sharaddarandale@ymail.com
}

\author{
Communicated : 17.02 .20
}

Revision : 25.3.20 \& 21.04.2020

Accepted : 20.05.2020

Published: 30.05 .2020

\begin{abstract}
:
The Delhi-Mumbai Industrial Corridor (DMIC) is major physical infrastructure project passing through six states of India. The ambitious DMIC has received major boost with India and Japan inking an agreement to set up a project development fund. The initial size of the Fund is 10 billion (US\$162.0 million). Both the Japanese and Indian Governments contribute equally. The Corridor intends to develop industrial estates and townships in various parts of the country in order to give thrust to manufacturing. Also, the Indian economy is rapidly undergoing urbanization. However, urbanization and industrialization have to go hand-in-hand for progress of a nation. The DMIC will play a prominent role in converging urbanization along with industrialization. The Corridor is estimated to create 2.3 million jobs, industrial output worth Rs 20 trillion along with efficient logistical network. Delhi-Mumbai Industrial Corridor is to be conceived as a Model Industrial Corridor of international standards with emphasis on expanding the manufacturing and services base and develop DMIC as the 'Global Manufacturing and Trading Hub'. The Government is considering this ambitious project to establish, promote and facilitate Delhi-Mumbai industrial corridor to augment and create social and physical infrastructure on the route which is world class and will help spurring economic growth of the region.
\end{abstract}

Key words: - Delhi-Mumbai Industrial Corridor, Model Industrial Corridor

\section{INTRODUCTION:}

The Delhi-Mumbai Industrial Corridor (DMIC) is major physical infrastructure project passing through six states of India. The ambitious DMIC has received major boost with India and Japan inking an agreement to set up a project development fund. The initial size of the Fund is 10 billion (US\$162.0 million). Both the Japanese and Indian Governments contribute equally. The Corridor intends to develop industrial estates and townships in various parts of the country in order to give thrust to manufacturing. Also, the Indian economy is rapidly undergoing urbanization. However, urbanization and industrialization have to go hand-in-hand for progress of a nation. The DMIC will play a prominent role in converging urbanization along with industrialization. The Corridor is estimated to create 2.3 million jobs, industrial output worth Rs 20 trillion along with efficient logistical network.

\section{What is DMIC?}

Delhi-Mumbai Industrial Corridor is to be conceived as a Model Industrial Corridor of international standards with emphasis on expanding the manufacturing and services base and develop DMIC as the 'Global Manufacturing and Trading Hub'. The Government is considering this ambitious project to establish, promote and facilitate Delhi-Mumbai industrial corridor to augment and create social and physical infrastructure on the route which is world class and will help spurring economic growth of the region.

\section{Background}

Government of India has announced establishing of the Multi-modal High Axle Load Dedicated Freight Corridor (DFC) between Delhi 
and Mumbai, covering an overall length of 1483 $\mathrm{km}$ and passing through the six States - U.P, NCR of Delhi, Haryana, Rajasthan, Gujarat and Maharashtra, with end terminals at Dadri in the National Capital Region of Delhi and Jawaharlal Nehru Port near Mumbai. Distribution of length of the corridor indicates that Rajasthan (39\%) and Gujarat (38\%) together constitute $77 \%$ of the total length of the alignment of freight corridor, followed by Haryana and Maharashtra $10 \%$ each and Uttar Pradesh and National Capital Region of Delhi $1.5 \%$ of total length each. This Dedicated Freight Corridor envisages a high-speed connectivity for High Axle Load Wagons (25 Tonne) of Double Stacked Container Trains supported by high power locomotives. The Delhi - Mumbai leg of the Golden Quadrilateral National Highway also runs almost parallel to the Freight Corridor. This corridor will be equipped with an array of infrastructure facilities such as power facilities, rail connectivity to ports en route etc. Approximately 180 million people, 14 percent of the population, will be affected by the corridor's development.

\section{Vision for DMIC}

The vision for DMIC is to create strong economic base with globally competitive environment and state-of-the-art infrastructure to activate local commerce, enhance foreign investments and attain sustainable development. Delhi-Mumbai Industrial Corridor is to be conceived as a Model Industrial Corridor of international standards with emphasis on expanding the manufacturing and services base and develop DMIC as the 'Global Manufacturing and Trading Hub'.

\section{Characteristics of Industrial Corridor}

Industrial Corridors recognize the interdependence of various sectors of the economy and offer effective integration between industry and infrastructure leading to overall economic and social development. Industrial corridors constitute world class infrastructure such as high-speed transportation (rail, road) network, ports with state-of- the-art cargo handling equipment, modern airports, special economic regions/ industrial areas, logistic parks/transhipment hubs, knowledge parks focused on feeding industrial needs, complementary infrastructure such as townships/ real estate, and other urban infrastructure along with enabling policy framework. Industrial corridor provides opportunities for private sector investment in the provision of various infrastructure projects associated with the exploitation industrial opportunity. However, the successful utilization of opportunities that arises from industrial corridors depends on availability of efficient transport and other infrastructure support systems. Corridor approach for industrial development primarily takes advantage of the existence of proven, inherent and underutilized economic -development potential within the influence region. Apart from the development of infrastructure, long term advantages to business and industry along the corridor include benefits arising from smooth access to the industrial production units, decreased transportation and communications costs, improved delivery time and reduction in inventory cost. The strategy of an industrial corridor is thus intended to develop a sound industrial base, served by world-class competitive infrastructure as a prerequisite for attracting investments into export oriented industries and manufacturing.

\section{DMIC Project Goals}

The developmental planning for DMIC aims to achieve certain end results with implementation that would ensure realization of envisaged vision for the project and lead to economic development. Accordingly the project goals for DMIC are:

- Double employment potential in five years (14.87\% CAGR) 
- Triple industrial output in five years (24.57\% CAGR)

\section{- Quadruple exports from the region in five} years (31.95\% CAGR)

\section{Sectors in focus}

For the Make in India campaign, the government of India has identified 25 priority sectors that shall be promoted adequately. These are the sectors where likelihood of FDI (foreign direct investment) is the highest and investment shall be promoted by the government of India.

\section{Current status of DMIC}

Highlighting that the Japanese government has committed USD 4.5 billion for the first phase of the project, laid across Uttar Pradesh, Haryana, Maharashtra, Gujarat, Madhya Pradesh and Rajasthan. The corridor project likely to be implemented in two phases namely - Phase-I \& Phase-II. An estimated $\$ 90$ to $\$ 100$ billion would be required to create the infrastructure in the first phase of the project. Japanese companies are expected to invest over $\$ 10$ billion in the proposed corridor during the first phase.

\section{Funding for DMIC}

- Govt. of India - 50\% (by way of a grant)Government of Japan- 50\% (by way of untied loans)- Funding from other sources such as beneficiary State Governments, Commercial Banks/ Financial Institutions/ Multilateral Agencies, shall be discussed and organized at a later stage, if required. In this regard, premier non-banking financial institutions of the country, including IL\&FS, have already shown interest and in due course contribution is also expected from commercial banks in India as well as FIIs. It is expected that Government of India's contribution to PDF shall be in the form of Grants/ through budgetary sources while Government of Japan's contribution to PDF will be as an untied loan from Japan Bank for International Cooperation (JBIC).

What is 'Make in India' program?
The 'Make in India' program is an initiative launched to encourage companies to increase manufacturing in India. This not only includes attracting overseas companies to set up shop in India, but also encouraging domestic companies to increase production within the country.

Policies under 'Make in India' initiative:

\section{New Initiatives:}

This initiative is to improve the ease of doing business in India, which includes increasing the speed with which protocols are met with, and increasing transparency.

\section{Foreign Direct Investment (FDI):}

The government has allowed 100\% FDI in all the sectors except Space (74\%), Defence (49\%) and News Media (26\%).FDI restrictions in tea plantation has been removed, while the FDI limit in defence sector has been raised from the earlier $26 \%$ to $49 \%$ currently.

\section{Intellectual Property Facts:}

The government has decided to improve and protect the intellectual property rights of

Innovators and creators by upgrading infrastructure, and using state-of-the-art technology.

\section{National manufacturing:}

Here the vision is, - to increase manufacturing sector growth to $12-14 \%$ per annum over the medium term.

- To increase the share of manufacturing in the country's Gross Domestic Product from 16\% to $25 \%$ by 2022 .

- To create 100 million additional jobs by 2022 in manufacturing sector.

- To create appropriate skill sets among rural migrants and the urban poor for inclusive growth.

- To increase the domestic value addition and technological depth in manufacturing.

- To enhance the global competitiveness of the Indian manufacturing sector.

- To ensure sustainability of growth, particularly with regard to environment. 


\section{Response to the 'Make in India' initiative:}

The government has said that it has, so far, received Rs 1,10 lakh crore worth of proposals from various companies that are interested in manufacturing electronics in India.

Companies like Xiaomi, Huawei have already set up manufacturing units in India, while iPhone, iPad manufacturer Foxconn is expected to open a manufacturing unit soon.

Recently, Lenovo also announced that it has started manufacturing Motorola smart phones in a plant near Chennai. In a report released by the World Bank, about a state-wise bifurcation based on ease of doing business, Gujarat was ranked as the top state, followed by Andhra Pradesh and Jharkhand.

\section{CONCLUSION:}

The plan is to develop new manufacturing cities, logistic hubs and residential townships along the DFC incorporating the philosophy of sustainability, connectivity and development; each manufacturing city will have world-class infrastructure, convenient public transport, power management and an efficient water and waste management system. Government of India is building a pentagon of corridors across the country to boost manufacturing and to project India as a Global Manufacturing destination of the world. The "Make in India" mission aims to remove policy and infrastructure bottle neck sand catapult India into a global manufacturing hub. Launched by the government of India in 2014 , it is expected to boost the manufacturing sector with a targeted GDP growth rate of 7.5 percent and increase productivity by $5 \%$. The program is also expected to provide millions of jobs and create an export-oriented economy to drive long -term, inclusive growth.

\section{References}

1. www.delhimumbaiindustrialcorridor.com

2. www.dmic.co.in

3. The times of India article dated on Dec 4, 2015

4. www.dmicdc.com

5. www.dnaindia.com

\begin{tabular}{|l|l|l|}
\hline Automobiles & Food Processing & Renewable Energy \\
\hline Automobile Components & IT and BPM & Roads and highways \\
\hline Aviation & Leather & Space \\
\hline Biotechnology & Media and Entertainment & Textiles and garments \\
\hline Chemicals & Mining & Thermal Power \\
\hline Construction & Oil and Gas & Tourism and Hospitality \\
\hline Defense manufacturing & Pharmaceuticals & Wellness \\
\hline Electrical Machinery & Ports & \\
\hline Electronic Systems & Railways & \\
\hline
\end{tabular}


Map for Proposed Investment Regions and Industrial Areas in the DMIC Region

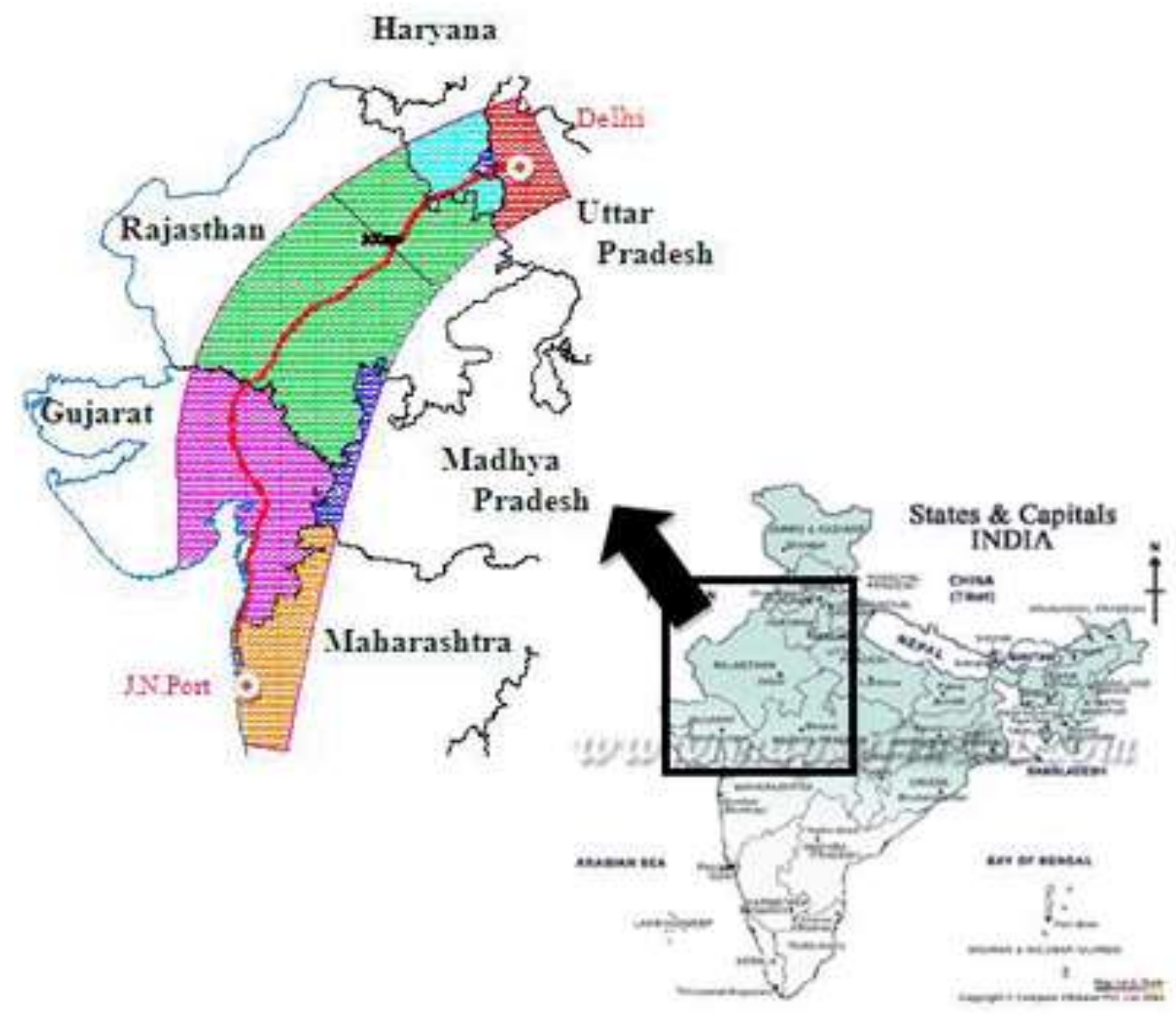

Status of other industrial corridors

\begin{tabular}{|c|c|c|c|c|}
\hline $\begin{array}{l}\text { Corridor } \\
\text { DMIC }\end{array}$ & $\begin{array}{r}\text { No of high } \\
\begin{array}{r}\text { potential districts } \\
\text { (total districts) }\end{array} \\
30(38)\end{array}$ & $\begin{array}{r}\text { Population } \\
\text { in } 2025 \\
\text { (million) } \\
133\end{array}$ & $\begin{array}{r}\text { GDP growth } \\
2014-25 . \\
\text { in } \% \\
7.4 \%\end{array}$ & $\begin{array}{l}\text { Type of economic activity } \\
\text { = Textiles } \\
\text { E Tourism } \\
\text { Eems \& jewellery }\end{array}$ \\
\hline AKIC & $18(19)$ & 104 & $6.9 \%$ & $\begin{array}{l}\text { - Textiles } \\
\text { Eoodprocessing } \\
\text { - Fertilisers }\end{array}$ \\
\hline СвIC & $11(14)$ & 56 & $6.8 \%$ & $\begin{array}{l}\text { - Automotive } \\
\text { - Consumer electronics } \\
\text { Leather }\end{array}$ \\
\hline CVIC & $7(7)$ & 31 & $6.4 \%$ & $\begin{array}{l}\text { - Food processing } \\
\text { Automobiles } \\
\text { - Chemicals \& petrochem }\end{array}$ \\
\hline MBIC & $7(11)$ & 53 & $7.1 \%$ & $\begin{array}{l}\text { Automobiles } \\
\text { Foodprocessing } \\
\text { Textiles }\end{array}$ \\
\hline
\end{tabular}

